\title{
Competitividade, Capacitação e Aprendizagem Tecnológica na Indústria de Máquinas Têxteis
}

\section{Neusa Serra}

Pesquisadora do Instituto de Pesquisas Tecnológicas de São Paulo-IPT

Doutora em Engenharia de Produção pela EPUSP

Rua Henrique Botticini, 99, CEP 05587-020 - São Paulo-SP

\section{Guilherme Ary Plonski}

Professor do Departamento de Engenharia de Produção - EPUSP

Av. Professor Almeida Prado, trav.2., no 128, CEP 05508-020 - São Paulo-SP

Palavras-chave: competitividade, capacitação tecnológica, aprendizagem.

key words: competitiveness, technological capability, aprenticeship.

\section{RESUMO}

Este artigo procura demonstrar como se dão as relações entre tecnologia e competitividade, a partir de um estudo exploratório da capacitação tecnológica na indústria brasileira de máquinas têxteis, realizado com base em pesquisa de campo em empresas selecionadas.

O estudo forneceu evidências de que a indústria brasileira de máquinas têxteis ė mais competitiva em produtos onde a evolução tecnológica tem se dado num ritmo mais lento e naqueles mais intensivos em trabalho e que requerem estreita relação com os clientes, como as máquinas de acabamento sob encomenda.

\section{ABSTRACT}

The purpose of this paper is to show the relationship between technology and competitiveness, out of an exploratory study of the tecnological capability of the Brazilian textile machine industry. The study was supported by a number of interviews in selected companies

Evidences from the study indicated that Brazilian textile machines that tended to be more competitive are those in which the technological progress tended to be slow and those whose production process requires more labor content and closer interactive relationship between producers and clients, such as finishing machines ordered by request. 


\section{PRODUÇÃO}

\section{Introdução}

A competitividade das empresas equivale ao grau de aceitação de seus produtos pelo mercado. Para a indústria têxtil brasileira, principal mercado das empresas produtoras de máquinas têxteis instaladas no país, o preço não é o único critério de escolha dos fornecedores de máquinas e equipamentos. Além deste, a parcela mais moderna da indústria têxtil, que dirige a produção tanto ao mercado interno quanto ao externo, leva em conta atributos como qualidade, flexibilidade $\mathrm{e}$ atualização tecnológica. A capacidade da indústria de máquinas têxteis de oferecer produtos que satisfaçam a esses requisitos depende, em boa medida, dos conhecimentos acumulados pelas empresas, o que evidencia a relação entre capacitação tecnológica e competitividade.

Mas a capacitação tecnológica, construída através de mecanismos de aprendizagem diversos, é condicionada, por sua vez, tanto por fatores externos quanto internos às empresas.

Com base numa pesquisa de campo realizada junto a fabricantes de máquinas têxteis (seis de máquinas para fiação e tecelagem, correspondendo ao universo de empresas dos dois segmentós e cinco de máquinas de acabamento, correspondendo a pelo menos $50 \%$ ), a representantes comerciais e a empresas têxteis, este artigo procura demonstrar como se dão as relações entre capacitação tecnológica e competitividade na indústria de máquinas têxteis e o papel desempenhado pelos condicionantes externos e internos nessa capacitação.

O periodo privilegiado pela análise vai de 1990 a 1994, quando a abertura comercial procedida no Brasil propicia 0 aumento das importações de máquinas. A penetração desigual das importações entre os segmentos de máquinas para fiação, tecelagem e acabamento de artigos têxteis coloca em relevo as diferentes capacidades de competir dos três segmentos, dadas, principalmente, pelas diferenças no grau de capacitação tecnológica atingido.

\section{Capacitação Tecnológica e Mecanismos de Aprendizagem}

A aprendizagem tecnológica, segundo BELL (1984, p. 187), é constituída dos "processos pelos quais as empresas adquirem habilidades e conhecimentos técnicos". Enquanto a aprendizagem refere-se às adições ao estoque de conhecimentos e habilidades já existente, este estoque é definido como "capacitação tecnológica" (FLEURY, 1994, p.34).

DAHLMAN et al. (1985), identificam três tipos de capacitaçâo tecnológica: em produção, em investimento e em inovação.

A capacitação em produção é a necessária para operar as instalações produtivas. Implica conseguir reunir e interpretar as informações do sistema de produção, incluindo as tentativas de adaptações e modificações e a 
compreensão de porque algumas coisas funcionam e outras não.

A capacitação em investimento está relacionada ao estabelecimento de novas instalações produtivas e à expansão das existentes, refletindo-se nos custos do projeto e na capacidade de sua adequação às circunstâncias do ambiente.

A capacitação em inovação consiste da criação de novas possibilidades técnicas, que tanto podem ser novas tecnologias quanto melhoramentos ou modificações nas existentes. Quando as empresas acumulam capacitação em produção e investimento, geralmente conseguem também desenvolver alguma capacitação em inovação.

BELL (1984) propõe uma tipologia para os mecanismos de aprendizagem mais voltada à inovação. Como DAHLMAN et al., a preocupação do autor é apreender os processos de aprendizagem tecnológicos característicos de países em desenvolvimento. Os mecanismos por ele elencados são: a) aprendizagem por operação (by operating), b) por mudança técnica (by changing), c) por sistemas de avaliação de desempenho, d) por treinamento, e) por contratação de pessoal, f) por busca (by searching).

O último mecanismo elencado é o aprendizado através da busca de conhecimentos externos, na forma de tecnologia "desincorporada", tanto de equipamentos quanto de pessoas. Esta busca se dá pela aquisição de informações tecnológicas e pelos contratos de transferência de tecnologia (consultorias externas, assistência técnica etc). Neste mecanismo, a identificação "de quem possui" o conhecimento adequado e o processo de negociação de sua compra são passos importantes.

\section{Fatores que Condicionam a Capacitação}

\subsection{Externos}

As indicações obtidas no estudo permitiram eleger a organização da indústria, a pressão da demanda e as políticas públicas como os principais condicionantes da capacitação externos à empresa.

A organização da indústria influi na capacitação principalmente pelo grau de concentração e pela propriedade do capital. Numa indústria concentrada as grandes empresas, que têm maior capacidade de manutenção de estruturas próprias de $P \& D$ e engenharia, normalmente conseguem impor restrições às licenciadas no processo de transferência. No que se refere à propriedade do capital, a influência se dá pela centralização das atividades tecnológicas dentro dos grupos. Apesar do acesso direto à tecnologia da matriz se constituir, em principio, em vantagem comparativa, a natureza normalmente apenas receptora das filiais pode representar um fator inibidor do desenvolvimento tecnológico dessas empresas. 


\section{PRODUÇÃO}

A pressão da demanda, por sua vez, deve ser destacada porque compele as empresas a oferecer produtos que satisfaçam as exigências dos consumidores, sejam eles finais ou representantes de outros elos da cadeia produtiva, estimulando o lançamento de novos e a diferenciação dos existentes.

O governo, através das políticas públicas, desempenha papel central na criação de um ambiente propício ao progresso tecnológico. Isto pode se dar, entre outros mecanismos, pelo estímulo à constituição de uma forte infra-estrutura tecnológica doméstica, pelo estabelecimento de canais de comunicação entre esta infra-estrutura e a indústria, pela formação de recursos humanos e pela instituição de um sistema de incentivos e penalidades ao desempenho industrial, representado pela adoção de políticas diferenciadas no nível fiscal, tributário e creditício visando a realocação de recursos de usos pouco eficientes para aqueles que mostrassem maior aderência aos objetivos de capacitação pré-estabelecidos.

\subsection{Internos}

No âmbito das empresas, os principais fatores estimuladores da capacitação tecnológica foram os próprios processos de aprendizagem e as estratégias competitivas e tecnológicas.

A intensidade e a diversidade da utilização dos mecanismos de aprendizagem já descritos influi no grau de capacitação.
No que se refere às estratégias competitivas, é preciso destacar que com o rápido avanço da concepção japonesa de produção flexível e em pequenos lotes, em oposição à produção americana em massa e padronizada, outras dimensões, além do preço e da qualidade, começaram a ganhar espaço. Estas novas dimensões referem-se ao tempo (muito associado a prazos de entrega), à confiabilidade (associada ao desempenho dos produtos e à observância dos prazos de entrega), à inovação e à flexibilidade.

FLEURY e MUSCAT (1992), apud FLEURY (1994) propõem uma tipologia das estratégias de competição que busca destacar tanto o seu caráter sequencial quanto a simultaneidade, ao destacar que a adoção de uma nova estratégia, ao contrário de ex́cluir, reforça a capacidade de competir com base nas anteriores. Esta tipologia, iniciada com a estratégia de custo, mostra a evolução das formas de competição, à medida que novas formas vão sendo agregadas: 1) custo; 2) custo e qualidade; 3) custo e qualidade e tempo; 4) custo e qualidade e tempo e flexibilidade; 5) custo e qualidade e tempo e flexibilidade e originalidade.

As estratégias de competição baseadas em qualidade, flexibilidade e originalidade requerem, em geral, estratégias tecnológicas ativas, para as quais a capacitação tecnológica préexistente é fundamental.

As estratégias tecnológicas, por sua vez, são definidas usualmente como o 
conjunto de políticas, planos e procedimentos para adquirir conhecimentos e habilidades, tendo em vista os objetivos da empresa. Este conjunto envolve, entre outras, definições a respeito do desenvolvimento próprio ou do licenciamento da tecnologia, da formação de alianças, da intensidade da mudança técnica (radical ou incremental) e da institucionalização ou não da atividade tecnológica.

FREEMAN (1982) propõe a seguinte tipologia de estratégias tecnológicas, que leva em conta tanto as condições do ambiente onde as empresas atuam quanto as atividades científicas e técnicas que realizam: a) ofensiva, b) defensiva, c) imitativa, d) dependente, e) tradicional, f) oportunista.

As estratégias ofensiva e defensiva são típicas de grandes empresas de países líderes e pressupõem a existência de fortes estruturas de $P \& D$ e engenharia que lhes possibilitem ser inovadoras (no primeiro caso) ou pioneiras na adoção de inovações (no segundo). As empresas de paises de industrialização tardia como o Brasil perseguem em geral estratégias imitativas, tradicionais, dependentes ou oportunistas.

As empresas que adotam a estratégia imitativa não contam com fortes estruturas de P\&D - embora possam contar com boas estruturas de engenharia - e suas inovações são geralmente de caráter incremental, representadas por melhoramentos em produtos ou processos. As que perseguem uma estratégia dependente obedecem a especificações dos clientes e fazem uso, quando necessário, de estruturas de P\&D e engenharia de outras firmas. As que adotam estratégias tradicionais contam com estruturas de engenharia mais precárias que as imitativas e realizam mudanças apenas "cosméticas" nos produtos. As empresas que perseguem estratégias oportunistas não contam com estruturas de $P \& D$ e têm precária capacidade em engenharia, mas são cápazes de explorar nichos de mercado não ocupados por outras firmas.

É importante, finalmente, destacar que estas categorias não são formas puras. Uma empresa multiprodutos pode adotar estratégias diferentes em um e em outro caso e estas podem variar ao longo do tempo.

\section{Resultados do Trabalho de Campo}

O aumento das importações na atual década se deu sobretudo nos teares (acréscimo de mais de 100\% de 1993 para 1994), equipamento no qual a evolução tecnológica, representada pelo aumento da velocidade e pelo emprego de dispositivos microletrônicos, tem se dado de forma muito rápida. No segmento de máquinas de acabamento a penetração das importações ocorreu de forma menos intensa. A produção nacional dessas máquinas ainda é considerada satisfatória, exceto naquelas destinadas à fabricação de artigos que exigem maior precisão e regularidade. 


\section{PROPUUÇÃO}

As alterações verificadas nos últimos dez anos revelam tanto a redução do espectro de equipamentos e componentes ofertados internamente - deixou-se de produzir no país filatórios open-end, teares a jato de ar, maquinetas para teares, foulards de acabamento e vários componentes - quanto a conformação da produção nacional naquela faixa de produtos de menor intensidade de uso de dispositivos microeletrônicos e de menor velocidade na substituição de modelos. São os casos das máquinas de preparação e de fiação, dos teares de baixa produtividade, para a produção em pequenos lotes, e dos equipamentos de acabamento de maior conteúdo relativo da parte mecânica, além dos componentes também mecânicos.

\subsection{Fontes de Tecnologia}

A indústria brasileira de máquinas têxteis tem no licenciamento e em seu próprio esforço interno as principais fontes de suprimento de tecnologia. $O$ licenciamento é largamente utilizado nos segmentos de máquinas para fiação e tecelagem e o esforço interno no segmento de máquinas de acabamento. Neste, as empresas se valem dos artifícios da engenharia reversa e do processo learning by doing para reproduzir aqui, com adaptações que dão especificidades às máquinas, modelos de equipamentos já difundidos mundialmente.

Mesmo considerando as enormes restrições representadas pela concentração do desenvolvimento tecnológico (e da própria indústria) no nível internacional, a capacitação atingida pela indústria brasileira de máquinas têxteis está aquém do que se poderia esperar, tendo em vista a sua tradição e algumas de suas características.

A fabricação de máquinas têxteis é uma das atividades precursoras da indústria brasileira de bens de capital; um dos fabricantes, ainda em operação, atua no setor desde a década de vinte e a maioria das empresas hoje existentes iniciou suas atividades entre as décadas de quarenta e sessenta. Além disso as unidades produtivas do setor são de médio e grande porte, abarcam amplo leque de produtos e sempre puderam ter acesso a uma variada gama de processos de aprendizagem.

\subsection{A concentração Internacional}

A concentração internacional da indústria de máquinas têxteis está relacionada às mudanças no comportamento da demanda. Estas, por sua vez, decorreram do declínio do consumo mundial de produtos têxteis a partir da década de setenta, que se refletiu sobre a estrutura de mercado do setor no nível internacional e determinou mudanças nas estratégias de competição das empresas têxteis. Nas décadas recentes, estas estratégias passaram a basear-se na diferenciação, na rápida resposta à demanda e na melhoria da qualidade dos produtos. Os principais produtores mundiais de máquinas têxteis responderam a esse movimento com a 


\section{PRODUÇÃO}

oferta de máquinas crescentemente mais flexiveis e velozes, além de extremamente mais produtivas. Em decorrência, foi intensificado o processo de concentração desta indústria no nivel mundial, por meio de fusões e incorporações entre os tradicionais fabricantes. Atualmente existem apenas sete fabricantes mundiais de máquinas para fiação e cerca de uma dezena de grandes empresas produtoras de teares. Estes fabricantes - alemães, italianos, suiços e japoneses - são também os detentores das tecnologias de última geração.

\subsection{Diferenças no Grau de} Capacitação Tecnológica Atingido pelas Empresas

Esta concentração, mais acentuada nos segmentos de fiação e tecelagem, tem reflexos sobre o grau de capacitação tecnológica dos fabricantes brasileiros. Nestes segmentos, as empresas de capital estrangeiro têm seu raio de possibilidades técnicas limitadas pela centralização das decisões dentro dos grupos dos quais fazem parte. Contam, por isso, com estruturas próprias de apôio tecnológico mais limitadas do que as empresas do segmento de acabamento. A parcela nacional (do segmento de tecelagem) é voltada a uma faixa de mercado menos nobre e praticamente não muda a sua linha de produtos. Para esta parcela, a demanda exerce menor pressão para o aumento da capacitação.

No segmento de máquinas de fiação, onde a produção nacional apresenta defasagem tecnológica menos pronunciada em relação à fronteira internacional, a demanda interna é menor, em virtude das seguintes razões: 1) na década passada ocorreu um razoável reequipamento das fiações brasileiras, que contam atualmente com um parque de máquinas tecnologicamente menos defasado que as tecelagens; 2) os investimentos em máquinas de fiação na década de noventa estão sendo mais voltados ao sistema open end, atualmente sem similar nacional (a produção brasileira dos filatórios desse tipo foi interrompida em 1992).

No segmento de máquinas de acabamento, no qual a concentração internacional é menor, o potencial competitivo é maior em função das características das máquinas e da produção sob encomenda. Apesar disso, há pouca ênfase em melhoramentos de processo e dificuldade no atendimento a solicitações de máquinas de beneficiamento mais sofisticado.

Este segmento que, junto com o de fiação (a anel), está sendo menos afetado pela abertura do mercado brasileiro e pela mudança de comportamento da demanda, conta com estruturas internas de apôio tecnológico - departamentos técnicos ou de engenharia - relativamente mais fortes que os demais, além de uma participação de engenheiros em cargos de gerência e supervisão proporcionalmente maior. É também o único que conseguiu adquirir capacitação em engenharia de projeto, indo além dos outros, que se restringiram 


\section{PRODUÇÃO}

ao domínio da engenharia de fabricação e de detalhamento. Na tipologia proposta por DALHMAN et al.(1985), os fabricantes de máquinas de acabamento acumularam capacitação em produção e alguma capacitação em inovação de produtos, enquanto os demais restringiram o seu aprendizado no nivel da produção.

\subsection{A Utilização de Mecanismos de Aprendizagem}

Tanto no segmento de máquinas para fiação e tecelagem quanto no de máquinas para acabamento as empresas não têm mecanismos para reter e potencializar o conhecimento "tácito" (não expresso e formalizado). Em quase todas as empresas os engenheiros estão distanciados do "chão da fábrica", os operadores não são estáveis, embora a manutenção de pelo menos um núcleo de operadores seja uma preocupação geral, e a polivalência é ou pouco enfatizada ou restrita a fases determinadas do processo produtivo.

Apesar de ter acumulado maior capacitação em inovação, o segmento de máquinas de acabamento não se distinguiu pela maior utilização de mecanismos de aprendizagem, a não ser os processos por operação e por mudança técnica (por ocasião do lançamento de novos produtos), que possibilitaram a larga exploração da engenharia reversa para a reprodução, com algumas modificações, de equipamentos já existentes. Os fabricantes dessas máquinas utilizaram menos o mecanismo de licenciamento de tecnologia do que os fabricantes das máquinas de fiação e tecelagem e, em decorrência, tiveram contato menos estreito com o meio externo.

A não exploração de processos de aprendizagem como consultorias externas, contratação de pessoal especializado, treinamento e sistemas de avaliação de desempenho, entre os demais elencados por BELL (1984), indica que a capacitação tecnológica atingida pelo segmento está aquém do que seria possivel numa estratégia claramente orientada nesse sentido.

Com a redução das barreiras tarifárias, a parcela da indústria têxtil com capacidade de investimento está se voltando muito mais às máquinas importadas, em primeiro lugar pela maior produtividade e economicidade no processo e em segundo pelas melhores condições de financiamento. Por outro lado, a vantagem da maior proximidade do comprador gozada pela indústria brasileira está sendo neutralizada, no segmento de máquinas para tecelagem, pela montagem de eficientes serviços pósvenda por parte dos fabricantes internacionais. Estes serviços incluem estruturas de engenharia para assistência técnica compativeis com os departamentos técnicos das empresas industriais aqui instaladas.

\subsection{A Influência das Estratégias Competitivas e Tecnológicas}

As empresas que contam com melhores estruturas internas de engenharia são também as que adotam 


\section{PRODUÇĀO}

estratégias competitivas baseadas em qualidade, flexibilidade (maior versatilidade do equipamento) e inovatividade (pioneirismo no lançamento de novos produtos no mercado brasileiro).

As que se destacam pelo pioneirismo no lançamento de novos produtos e modelos no mercado brasileiro são as que adotam a estratégia tecnológica imitativa. As que competem com base em preços perseguem estratégias tradicionais, praticamente não mudam a linha de produtos e, mesmo quando isto ocorre, as mudanças são muito pouco significativas.

\section{Conclusões}

A baixa competitividade das máquinas têxteis brasileiras é demonstrada pela perda de mercado para os produtos importados nos anos noventa, quando saem de cena os mecanismos tarifários de proteção. De 1993 para 1994 as importações de máquinas têxteis aumentaram em $100 \%$, subindo de US\$ 254,8 para US\$ 512,2 milhões. A penetração das importações de máquinas de fiação, tecelagem e acabamento foi desigual, tendo concorrido para isso as seguintes razões: a) a maior velocidade das inovaçóes tecnológicas em equipamentos como os teares, cujos últimos modelos não têm similar nacional eb) as diferentes capacidades de competir entre os segmentos da indústria de máquinas.

A capacidade da indústria brasileira de máquinas têxteis de oferecer produtos competitivos tanto em preços quanto em requisitos de qualidade, flexibilidade e atualização tecnológica revelou-se fraca em linhas gerais, mas com diferenças significativas entre linhas de produtos e empresas ofertantes. Os segmentos de máquinas de fiação e de acabamento mostraram-se mais competitivos que o de máquinas para tecelagem, sendo que o segmento de máquinas de acabamento revelou maior acúmulo de capacitação tecnológica.

Apesar de ter alcançado capacitação em produção e alguma em inovação, a indústria de máquinas têxteis mostrou-se refratária à introdução de inovações organizacionais. As empresas não utilizam sistemas de gestão da qualidade, a integração entre as áreas de projeto e manufatura é precária e não existem mecanismos para estruturar e reter adequadamente $o$ conhecimento já acumulado.

As vantagens apresentadas pelo segmento de máquinas de acabamento, a despeito das fragilidades na gestão e da não exploração de vários mecanismos de aprendizagem, só podem ser compreendidas a partir de uma perspectiva que leve em conta as condições ou fatores que influem sobre a capacitação.

Dentro da condição representada pela organização da indústria, o principal aspecto de diferenciação entre as empresas é a origem do capital. $O$ segmento de máquinas de fiação é composto por filiais (além de uma coligada) de empresas 


\section{PRODUÇÃO}

internacionais; o de máquinas para tecelagem é híbrido, além das subsidiárias, duas empresas nacionais também atuam no segmento, dirigindose estrategicamente ao chamado "mercado de segunda linha"; no segmento de acabamento predominam as empresas nacionais, de propriedade familiar e estrutura organizacional do tipo funcional.

As filiais de empresas internacionais, dependentes de decisões da matriz, contam com departamentos de engenharia relativamente mais modestos, cujo papel se restringe à decodificação das informações recebidas e seu repasse à àrea de manufatura. Questões estratégicas, como definições sobre quais produtos produzir e para quais mercados, estão em geral fora do alcance das filiais locais.

O segmento de máquinas de acabamento, com poucas empresas internacionais, conta menos com as limitações representadas pelas relações com a matriz e é beneficiado, do ponto de vista da aprendizagem tecnológica, pelo caráter sob encomenda da produção. Este caráter obriga a uma interação muito mais estreita com o cliente, da qual resultam ganhos para ambas as partes, e abre possibilidades de maior diferenciação de produtos. Em tese, no segmento de acabamento "cada máquina é uma máquina". Esta singularidade requer tanto o domínio da tecnologia de projeto quanto maiores habilidades dos operadores na fabricação das partes e peças e na montagem das máquinas.
As possibilidades de diferenciação, em produtos sob encomenda, são, por definição, maiores que nos seriados. A diferenciação nos segmentos de fiação e tecelagem é praticamente restrita ao emprego de acessórios que conferem maior versatilidade às máquinas. $\mathrm{O}$ projeto básico, dentro de cada modelo, é o mesmo.

A demanda exerceu, historicamente, pouca pressão no sentido de aumentar a capacitação tecnológica da indústria de máquinas têxteis em geral. A parcela da indústria têxtil que sempre se voltou ao fornecimento interno de máquinas $\mathrm{e}$ equipamentos é constituída das milhares de pequenas e médias empresas descapitalizadas. Para esta parcela a produtividade $\mathrm{e}$ a atualização tecnológica dos equipamentos não são atributos fundamentais; o preço (e, no caso das empresas voltadas ao mercado de moda, a versatilidade) é em geral o critério determinante na compra. Por outro lado, a indústria têxtil brasileira como um todo, voltada preferencialmente a um mercado interno protegido, não se caracterizou pela renovação periódica de sua capacidade instalada, optando por operar com equipamentos já antigos e obsoletos na maior parte do tempo.

Existem também diferenças significativas entre empresas de um mesmo segmento, decorrentes das estratégias tecnológicas que elas perseguem e das estratégias de competição que elegeram para manter e expandir seus mercados. 


\section{PRỌDUÇÃO}

A acomodação na oferta de produtos tecnologicamente defasados e de baixo preço não exige de algumas empresas esforços significativos de capacitação tecnológica, o que se reflete em suas modestas estruturas internas de engenharia. Estas empresas, presentes tanto no segmento de máquinas para tecelagem quanto no de máquinas de acabamento, perseguem estratégias tradicionais e oportunistas (esta última, no caso das empresas que produzem dispositivos para reaproveitamento de teares antigos) e mostram-se vulneráveis à concorrência das importações, tanto de produtos novos similares, provenientes principalmente do sudeste asiático, quanto de equipamentos usados de várias procedências.

As empresas que se aproximam mais da estratégia imitativa lançam novos produtos no mercado brasileiro a intervalos menores de tempo e guardam "memórias" detalhadas dos projetos, indicando maior formalização das rotinas na área de engenharia. Estas empresas adotam estratégias de competição que privilegiam a qualidade, a flexibilidade $\mathrm{e}$ a atualização tecnológica dos produtos, além de, em alguns casos, o tempo de resposta dos pedidos.

Finalmente, vale destacar a ausência de estímulos governamentais para a construção da capacitação tecnológica na indústria. A longa proteção tarifária desfrutada pelo setor têxtil brasileiro estendeu-se, embora em menor intensidade, também ao de máquinas têxteis. Mas esse longo período de proteção não teve por finalidade a preparação do setor para uma fase posterior de abertura comercial. Ao contrário, dentro do projeto nacional de substituir importações, passou-se a produzir internamente praticamente todos os tipos de máquinas têxteis, em escalas nem sempre econômicas e a custos muitas vezes elevados. A reestruturação em curso hoje no setor busca, como ponto de partida, a redução de custos e a escala mínima. A efetiva inserção das empresas ou segmentos da indústria numa condição competitiva dependerá principalmente, por sua vez, da capacitação tecnológica atingida em cada caso.

\section{Referências Bibliográficas}

BELL, $M$. Learning and the accumulation of industrial technological capacity in developing countries. In: FRANSMAN, M.; KING, K. (Eds) Technological capability in the third world. New York, St. Martin, 1984. p. 187-209, cap.4

DAHLMAN, C.J.; ROSS-LARSON, B.; WESTPHAL, L.E. Managing technological development: lessons from the newly industrializing countries. Washington D.C., World Bank, 1985. 55p. (Word Bank Staff Working Paper n.717)

FLEURY, A. Qualidade, produtividade e competitividade: abordagem comparativa entre França e 


\section{PRODUÇÃO}

Brasil. Revista de Administração, v.29, n.2, p.20-31, abr./jun. 1994.

FREEMAN, C. The economics of industrial innovation. 2.ed. Cambridge Mass., MIT Press, 1982. Cap. 7-8, p. 14886.

SATO, H. Máquinas: o alicerce para a industrialização. Textília-Têxteis Interamericanos, v.5, n.18, p.24-7, set./ nov. 1995. 